\title{
Priority Program for Improving Service Quality Based on Student Satisfaction
}

\author{
I Ketut Sudiartha*, I Made Sudana, I Made Ariana, Ni Ketut Masih \\ Accounting Department \\ State Polytechnic of Bali \\ Badung, Indonesia \\ *ketutsudiartha@pnb.ac.id
}

\begin{abstract}
Measurement of the satisfaction of students to education service quality needs to be done by the institution. The measurement results of student satisfaction will use as a basis in determining priority programs by the institution in improving the education service quality. This study intended to describe student satisfaction of education service quality and the determination of priority programs to improve education service quality based on an assessment of student satisfaction levels. The model used is a descriptive study model. The data used in this study were obtained from primary and secondary sources in the form of quantitative data. Quantitative data consisted of the result of the assessment of student satisfaction in service quality. The research instrument in the form of the student satisfaction of service quality questionnaire. The questionnaire follows the service quality model that includes aspects of reliability, responsiveness, assurance, empathy. The questionnaire uses 4 Likert scales, from 1 (not good) to 4 (very good). This study involved 297 respondents who were students majoring in accounting at the Bali State Polytechnic. The sampling technique used was stratified random sampling based on the academic year the student was registered. The study used descriptive analysis techniques. Describe the student satisfaction of service quality using percentage analysis by comparing the answers with ideal answers in the same item and also describe the student satisfaction of service quality by using the cartesian diagram. The results of the study are students satisfied with the quality of educational services in general, but there are some dimensions of service quality that needed to improve. Priority program for improving the quality service can be done by the improvement of the learning room and facilities, increase competence and increase teaching skills of lecturers, the improvement of the learning process and examinations assessment, and the improvement of the quality and quantity of library materials.
\end{abstract}

Keywords—program, service, quality, student, satisfaction

\section{INTRODUCTION}

The success of higher education depends on the ability of higher education to provide services according to expectations of education consumers and the higher education ability to produce products that satisfy people who use educational services [1]. Therefore, Higher education strives to provide quality services according to user expectations.
Students are one of the higher education service stakeholders. Students as the primary stakeholders have various needs and expectations for educational services. The student needs and expectations need to be understood by the higher education to meet or exceed student expectations [2].

Quality of educational services is an effort made by educational institutions to meet expectations of creating customer satisfaction in education [3]. Students' perceptions of the quality of educational services need to be assessed by the Higher education. Higher education may use the results of this assessment to adjust the services provided to meet or exceed student expectations.

Service quality dimensions have a strong relationship with the students' satisfaction [4,5]. Student satisfaction is an indicator of quality in higher education [6]. Student satisfaction is one element of the education quality monitoring used by higher education institutions [7]. Student satisfaction as a user needs to be evaluated periodically. According to BAN-PTN (National Accreditation Board for Higher Education) standards, the level of user satisfaction on the aspects of reliability, responsiveness, assurance, empathy, and tangible is $\geq 75 \%$.

Educational institutions must deliberately manage educational services so that they exceed student expectations because this does not happen automatically [2]. Educational institutions must make priority programs to improve the quality of educational services to increase student satisfaction. According to BAN-PTN (National Accreditation Board for Higher Education), the measurement results of student satisfaction are analyzed and followed up at least two times each semester and used to improve the learning process and show an increase in learning outcomes.

Considering the strong relationship between service quality and student satisfaction, and also the importance of priority programs to improve service quality, it is necessary to assess the level of student satisfaction with service quality as the basis for determining priority programs for improving the service quality. Measurement of the level of student satisfaction 
includes the aspects of reliability, responsiveness, assurance, empathy, and tangibility.

This study intended to describe the student's satisfaction with education service quality and the determination of priority programs to improve education service quality based on an assessment of student satisfaction levels.

\section{RESEARCH METHODS}

The research model used is a descriptive research model by describing the student's satisfaction with education service quality and the determination of priority programs to improve education service quality based on an assessment of student satisfaction levels. The data used in this study were obtained from primary and secondary sources in the form of quantitative data. Quantitative data consisted of the result of the assessment of student satisfaction in service quality. The research instrument in the form of the student satisfaction of service quality questionnaire. The questionnaire follows the service quality model that includes aspects of reliability, responsiveness, assurance, empathy [8] following the provisions of BAN-PTN. Questioner consists of 40 question items. The questionnaire uses 4 Likert scales, from 1 (not good) to 4 (very good). This study involved 297 respondents who were students majoring in accounting at the Bali State Polytechnic. The sampling technique used was stratified random sampling based on the academic year the student was registered.

The analysis techniques used are descriptive analysis. Describe the student satisfaction of service quality using percentage analysis by comparing the answers with ideal answers in the same item and also describe by using the cartesian diagram. The cartesian chart consisted of four quadrants bounded by two lines that intersect perpendicularly at points $(\mathrm{X}, \mathrm{Y})$. The $\mathrm{X}$-axis is the performance/implementation score, and $\mathrm{Y}$-axis is the importance/expectation score. The cartesian diagram is shown as follows in Figure 1.

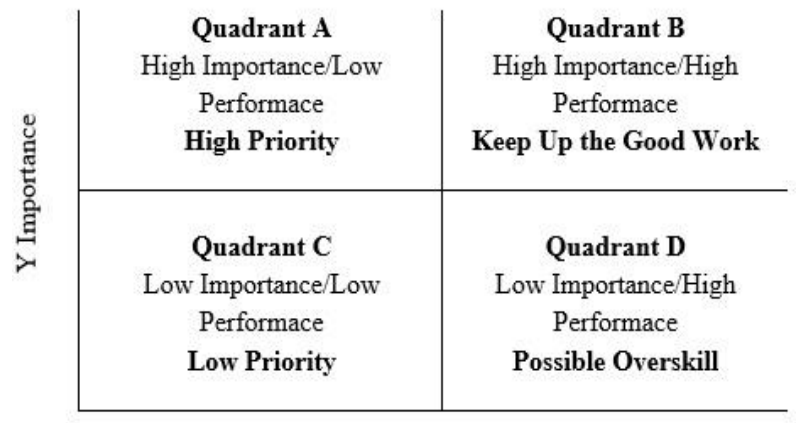

X Performance

Fig. 1. Cartesian diagram.

\section{RESULTS AND DISCUSSIONS}

The quality of educational services is an effort made by educational institutions to meet expectations of creating customer satisfaction in education. Improving service quality to provide excellent service requires the following four things: (1) customers and their expectations, (2) performance improvement, (3) process improvement, and (4) culture that supports continuous improvement. Customers and their expectations are the service organization that identifies customer expectations, sets priorities, then establishes criteria for judging success. Performance improvement is a service organization that identifies and implements performance, recognizes, and awards. Process improvement is service organizations identify process problems that can affect customer satisfaction, diagnose causes, identify, and test solutions or improvements. The culture that supports continuous improvement, the service organization strengthens the organizational culture so that it can support continuous improvement of service quality [8].

Measurement of customer satisfaction is important to be able to find out the product/service attributes that make customers satisfied, and product/service attributes that make customers dissatisfied [9]. Customer satisfaction is a function of the gap between the customer expected service and customer received services. The service expected depends on word of mouth information, personal needs, and past experiences, while the service received depends on the dimensions of service quality. A comparison of the expected service with the service received raises the perception of service quality. The quality measurement method uses five dimensions of service quality known as the service quality method which consists of tangibility, reliability, responsiveness, assurances, and empathy [10].

\section{A. Student Satisfaction with the Quality of Education Services}

Management of educational institutions must have a comprehensive understanding of the needs and expectations of students first [2], namely reliability, namely the ability of educational institutions to carry out services accurately and reliably following the promised. Responsiveness refers to the willingness and ability to help service users (students, stakeholders, and society) and respond to their requests quickly. Assurance is a guarantee that includes knowledge, competence, politeness, and respect for students. Guarantees have a trustworthy nature, free from danger and doubt. Empathy means that educational institutions are willing to care and to give personal attention to service users (students, stakeholders, and society) and have comfortable operating hours. Tangibles relate to the appearance of physical facilities, equipment/supplies, personnel, and communication materials [3].

The following will describe the results of the percentage analysis and cartesian diagrams for each of the quality dimensions and the overall quality dimension. 
TABLE I. ASSESSMENT OF TANGIBILITY DIMENSIONS

\begin{tabular}{|l|l|l|}
\hline \multirow{2}{*}{$\begin{array}{c}\text { Tangibility } \\
\text { Dimensions }\end{array}$} & Expectation & Reality \\
\cline { 2 - 3 } & Score (\%) & Score $(\%)$ \\
\hline $\mathrm{Ta} 1$ & 3.87 & 3.05 \\
\hline $\mathrm{Ta} 2$ & 3.84 & 3.02 \\
\hline $\mathrm{Ta} 3$ & 3.74 & 3.11 \\
\hline $\mathrm{Ta} 4$ & 3.69 & 3.13 \\
\hline $\mathrm{Ta} 5$ & 3.52 & 3.08 \\
\hline $\mathrm{Ta} 6$ & 3.56 & 3.02 \\
\hline $\mathrm{Ta} 7$ & 3.49 & 3.18 \\
\hline $\mathrm{Ta} 8$ & 3.52 & 3.13 \\
\hline $\mathrm{Ta} 9$ & 3.52 & 3.05 \\
\hline $\mathrm{Ta} 10$ & 3.57 & 3.05 \\
\hline $\mathrm{Ta} 11$ & 3.77 & 3.02 \\
\hline
\end{tabular}

Based on the data in Table 1, it can be said that the tangibility dimensions are good, but there are considerable gaps between expectations and realization for Ta1 (the lecture room used for lectures), Ta2 (teaching and learning facilities in the lecture room), and Ta11 (library materials are available in the library) which could cause dissatisfaction.

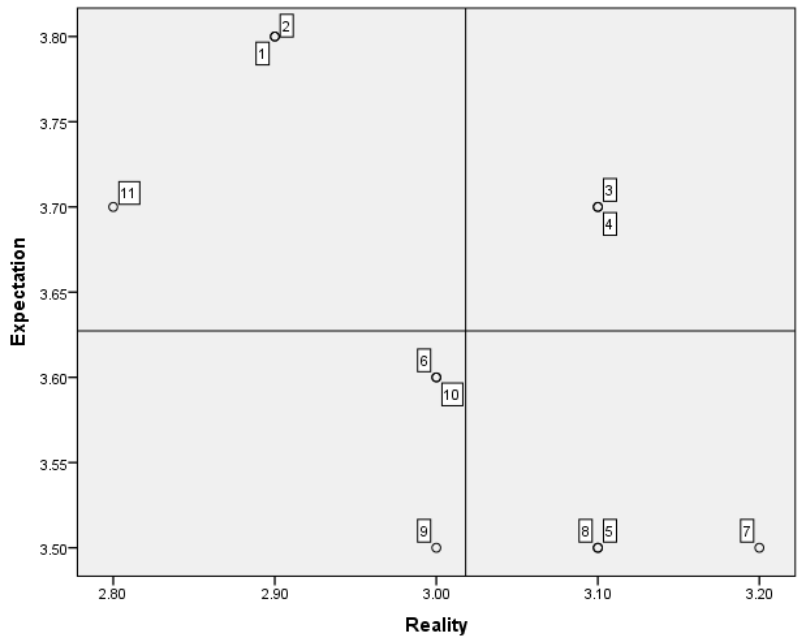

Fig. 2. Cartesian diagram of tangibility dimensions.

The components of the tangibility dimension of service quality that are in quadrant A (high priority) are Ta1 (the lecture room used for lectures), Ta2 (teaching and learning facilities in the lecture room), and Ta11 (library materials are available in the library). The components of the tangibility dimension of service quality that are in quadrant $\mathrm{C}$ (low priority) are Ta6 (service facilities used in the department), Ta9 (library service room in the library), and Ta10 (the facilities used in the library) (Figure 2).
TABLE II. ASSESSMENT OF RELIABILITY DIMENSIONS

\begin{tabular}{|l|l|l|}
\hline \multirow{2}{*}{$\begin{array}{c}\text { Reliability } \\
\text { Dimensions }\end{array}$} & Expectation & Reality \\
\cline { 2 - 3 } Score $(\%)$ & Score $(\%)$ \\
\hline Re1 & 3.80 & 3.18 \\
\hline Re2 & 3.84 & 3.03 \\
\hline Re3 & 3.84 & 3.00 \\
\hline Re4 & 3.57 & 3.07 \\
\hline Re5 & 3.52 & 3.03 \\
\hline Re6 & 3.70 & 3.05 \\
\hline Re7 & 3.67 & 3.11 \\
\hline Re8 & 3.49 & 3.05 \\
\hline Re9 & 3.57 & 3.05 \\
\hline $\operatorname{Re} 10$ & 3.44 & 3.00 \\
\hline $\operatorname{Re} 11$ & 3.54 & 3.00 \\
\hline
\end{tabular}

Based on the data in Table 2, it can be said that the reliability dimensions are good, but there are considerable gaps between expectations and realization for $\operatorname{Re} 2$ (the reliability of the lecturer in giving examples), $\operatorname{Re} 3$ (the ability of the lecturer in teaching practicum), Re6 (the reliability dimension of the equipment used for practicum), Re10 (the ability of library staff in-service), and Re11 (reliability of library information) which could cause dissatisfaction.

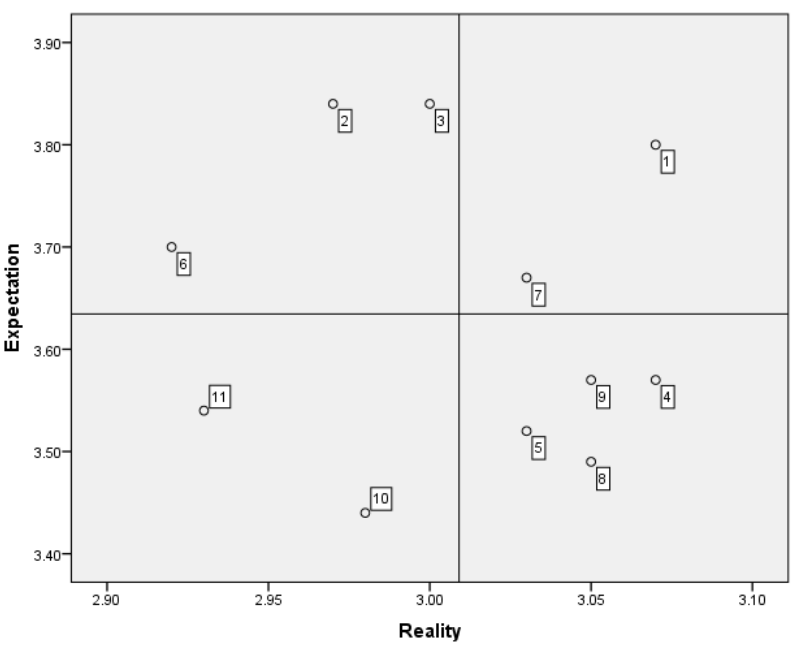

Fig. 3. Cartesian diagram of reliability dimensions.

The components of service quality reliability dimension in quadrant A (high priority) are $\operatorname{Re} 2$ (the reliability of the lecturer in giving examples), Re3 (the ability of the lecturer in teaching practicum), and Re6 (the reliability dimensions of the equipment used for practice). The components of service quality reliability dimension in quadrant $\mathrm{C}$ (low priority) are Re10 (the ability of library staff in-service), and Re11 (reliability of library information) (Figure 3). 
TABLE III. ASSESSMENT OF RESPONSIVENESS DIMENSIONS

\begin{tabular}{|l|l|c|}
\hline $\begin{array}{c}\text { Responsiveness } \\
\text { Dimensions }\end{array}$ & Expectation & Reality \\
\cline { 2 - 3 } Score (\%) & Score (\%) \\
\hline Rs1 & 3.70 & 3.02 \\
\hline Rs2 & 3.74 & 3.00 \\
\hline Rs3 & 3.70 & 3.13 \\
\hline Rs4 & 3.70 & 3.12 \\
\hline Rs5 & 3.61 & 3.02 \\
\hline Rs6 & 3.57 & 3.00 \\
\hline
\end{tabular}

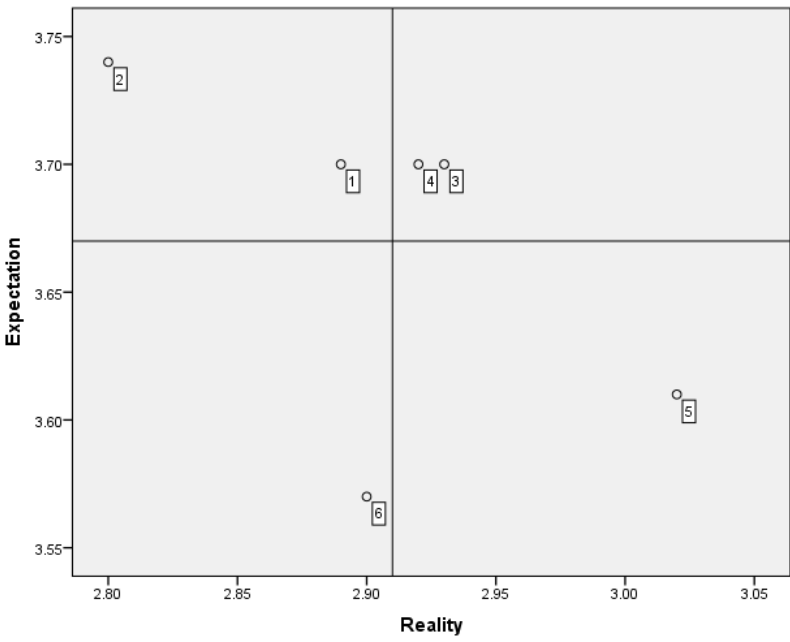

Fig. 4. Cartesian diagram of responsiveness dimensions.

Based on the data in Table 3, it can be said that the responsiveness dimensions are good, but there are considerable gaps between expectations and realization for Rs1 (lecturer responsiveness to students' physical abilities), Rs2 (lecturer responsiveness to students with less learning absorption), dan Rs6 (responsiveness of library staff to student needs) which could cause dissatisfaction.

The components of the responsiveness dimension of service quality in quadrant A (high priority) are Rs1 (lecturer responsiveness to students' physical abilities), and Rs2 (lecturer responsiveness to students with less learning absorption). The component of the responsiveness dimension of service quality in quadrant $\mathrm{C}$ (low priority) is Rs6 (responsiveness of library staff to student needs) (Figure 4).

TABLE IV. ASSESSMENT OF ASSURANCE DIMENSIONS

\begin{tabular}{|c|c|c|}
\hline $\begin{array}{c}\text { Assurance } \\
\text { Dimensions }\end{array}$ & Expectation & Reality \\
\cline { 2 - 3 } & Score (\%) & Score (\%) \\
\hline As1 & 3.66 & 3.30 \\
\hline As2 & 3.72 & 3.21 \\
\hline As3 & 3.77 & 3.10 \\
\hline As4 & 3.72 & 3.28 \\
\hline As5 & 3.54 & 3.21 \\
\hline As6 & 3.51 & 3.18 \\
\hline
\end{tabular}

Based on the data in Table 4, it can be said that the assurance dimensions are good, but there are considerable gaps between expectations and realization for As2 (guarantee that the exam assessment is objective), and As3 (guarantees that the implementation of the learning process is properly) which could cause dissatisfaction.

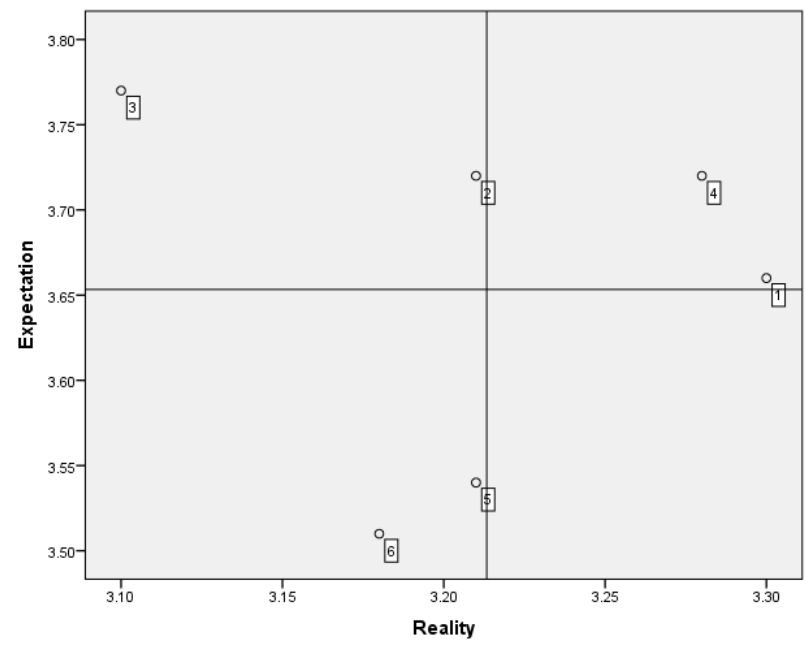

Fig. 5. Cartesian diagram of assurance dimensions.

The components of the service quality assurance dimension in quadrant A (high priority) are As2 (guarantee that the exam assessment is objective), and As3 (guarantees that the implementation of the learning process is properly). The components of the service quality assurance dimension in quadrant $\mathrm{C}$ (low priority) are As5 (BAAK staff guarantees to serve well), and As6 (guarantee the library staff serves well) (Figure 5).

TABLE V. ASSESSMENT OF EMPATHY DIMENSIONS

\begin{tabular}{|l|l|l|}
\hline \multirow{2}{*}{$\begin{array}{c}\text { Assurance } \\
\text { Dimensions }\end{array}$} & Expectation & Reality \\
\cline { 2 - 3 } & Score $\mathbf{( \% )}$ & Score $\mathbf{( \% )}$ \\
\hline Em1 & 3.72 & 2.57 \\
\hline Em2 & 3.54 & 3.00 \\
\hline Em3 & 3.59 & 3.02 \\
\hline Em4 & 3.61 & 3.00 \\
\hline Em5 & 3.56 & 3.02 \\
\hline Em6 & 3.54 & 2.84 \\
\hline
\end{tabular}

Based on the data in Table 5, it can be said that the empathy dimensions are good, except for Em1 (the attention of the lecturers to students who are not smart enough) and Em6 (the library staff's attention to the lack of library books). 


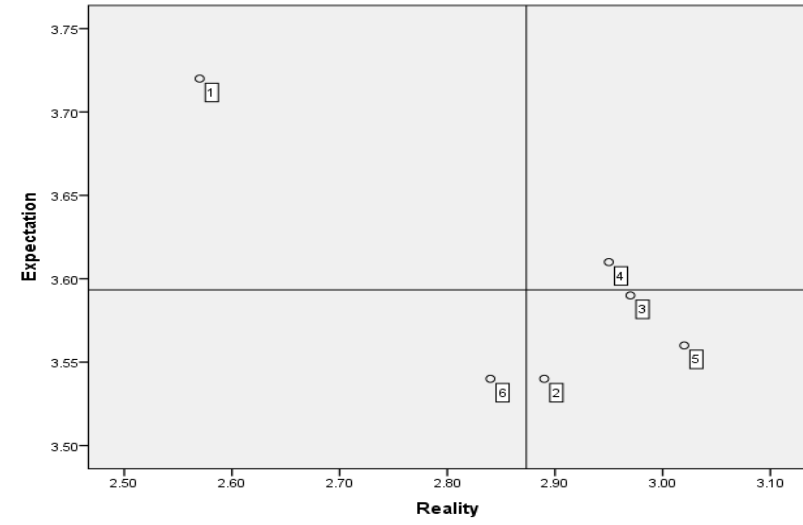

Fig. 6. Cartesian diagram of empathy dimensions

The component of the empathy dimension of service quality in quadrant A (high priority) is Em1 (the attention of the lecturers to students who are not smart enough). The component of the responsiveness dimension of service quality in quadrant $\mathrm{C}$ (low priority) is Em6 (the library staff's attention to the lack of library books) (Figure 6).

When viewed as a whole, the tangibility dimensions in quadrant A (high priority) are Ta1 (lecture rooms used for lectures), and $\mathrm{Ta} 2$ (teaching and learning facilities in the lecture room) and Ta11 (library materials available). The reliability dimensions in quadrant $\mathrm{A}$ are Re13 (lecturer reliability in providing examples), Re14 (the ability of lecturers to teach practicum), Re17 (the reliability of the equipment used in practice), and Re18 (the reliability of academic information in the department). The responsiveness and empathy dimensions in quadrant A are Rs23 (the responsiveness of the lecturer to the student's physicality), Rs24 (the responsiveness of the lecturer to the student's less learning absorption), Rs25 (the responsiveness of the technician to the laboratory readiness), Rs26 (the responsiveness of the department to the availability of learning), and Em35 (lecturer attention to less intelligent students) (Figure 7)

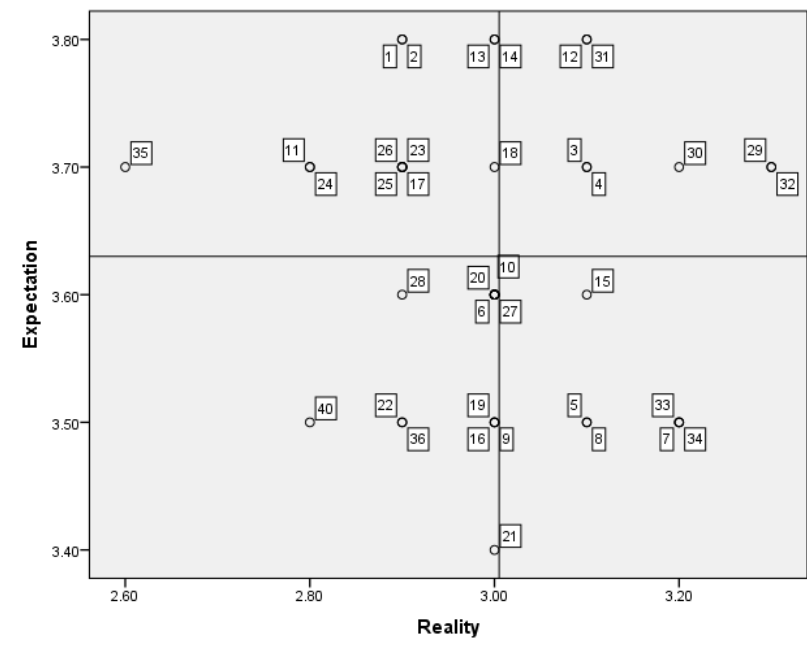

Fig. 7. Cartesian diagram of entirety dimensions.
When viewed as a whole, the tangibility dimensions in quadrant $\mathrm{C}$ (low priority) are Ta6 (service facilities used in the department), Ta9 (library service room in the library, and Ta10 (facilities used in the library). The reliability dimensions in quadrant $\mathrm{C}$ are $\operatorname{Re} 16$ (the ability of department technicians in service), Re19 (staff ability in service), Re20 (academic information reliability), $\operatorname{Re} 21$ (libraries staff ability in service), and $\operatorname{Re} 22$ (the reliability of library information in the library). The responsiveness and empathy dimensions in quadrant $\mathrm{C}$ are Rs27 (responsiveness of staff in serving students), Rs28 (library staff responsiveness to student needs), Em36 (attention lecturers to active student organizations), Em37 (attention technicians to the absence of lab equipment), Em38 (the attention of department staff to learning facilities), Em39 (attention of staff to underprivileged students), and Em40 (attention of library staff to the library materials).

\section{B. Education Service Quality Improvement Priority Programs}

Implementation of quality improvement programs needs technology support. The use of technology can increase student and faculty satisfaction [11]. Service quality influence the university image and student satisfaction [12]. Besides affecting institutional reputation and student' satisfaction, service quality also influences students' loyalty [13-15]. Service quality is important to an academic institution for acquiring popularity, attracting funds, challenging other institutions, facing global competition and, competing for better rankings [16].

In general, the score for the quality of academic services is good but still lower than expectations. Therefore it is necessary to have programs to improve the service. The priority program needed regarding the tangible aspect is to improve the learning room and facilities such as lecture rooms, lecture room facilities, library facilities, and other facilities. Classrooms and facilities that meet quality standards and the availability of adequate facilities will affect service quality.

The priority program needed regarding aspects of reliability is to increase lecturer competence in teaching practice. The ability of lecturers to provide real examples and teaching practice will increase according to student expectations. Besides, it is also necessary to increase librarian competence and improve library information systems so that librarians can provide good services with the support of adequate information systems. For this reason, it is necessary to update the knowledge and skills of the lecturers to use various and appropriate methods in teaching and assessment activities [17]. Quality of teaching will affect student satisfaction [18].

The priority program needed regarding the responsiveness aspect is to increase the teaching skills of lecturers. Adequate teaching skills of lecturers will encourage lecturers to be more responsive to students' physicality and the student's less learning absorption. Student satisfaction is not only influenced by academic aspects, non-academic aspects, and reputation $[5,19]$. 
The priority program to improve aspects of assurance is improving the learning process and examinations assessment so that the learning process runs well, and examination assessments are carried out objectively. It is also necessary to improve the quality of library staff to provide quality services. Qualified staff delivers better service to students [20].

The priority program to improve empathy aspects is the improvement of the librarian's attention to the quality and quantity of library materials in the library. Student perceptions of the academic, social, and environmental aspects correlated with overall satisfaction [21].

\section{CONCLUSION}

The purpose of the study is to describe the satisfaction of students with education service quality and the determination of priority programs to improve education service quality in the Accounting Department PNB. The results of the study are students satisfied with the quality of educational services in general, but there are some dimensions of service quality that needed to improve. Priority program for improving the quality service can be done by the improvement of the learning room and facilities, increase competence and increase teaching skills of lecturers, the improvement of the learning process and examinations assessment, and the improvement of the quality and quantity of library materials.

\section{ACKNOWLEDGMENT}

The author would like to thank the Bali State Polytechnic for the research funding and the opportunity to provide input on the service quality improvement program.

\section{REFERENCES}

[1] S. Rabiah, S. Rabiah, and U. M. Indonesia, "Management of Higher Education in Improving the Quality of Education," vol. 6, no. 1, pp. 5867, 2019.

[2] S. A. Menon, "Enhancing Service Quality in Higher Education," vol. 5, no. 5, pp. 55-60, 2015, doi: 10.9790/7388-05525560.

[3] V. A. Zeithaml and L. L. Berry, "A Conceptual Model of Service Quality and its Implication for Future Research ( SERVQUAL )," no. September 2014, 1985, doi: 10.2307/1251430.

[4] S. Pohyae et al., "The Relationship Between Service Quality and Student Satisfaction: The Case of International Students in Public University," vol. 34 , no. 4, pp. 491-498, 2016, doi 10.5829/idosi.wasj.2016.34.4.15684

[5] A. Azam, "Service Quality Dimensions and Students' Satisfaction: A study of Saudi Arabian Private Higher Education Institutions," vol. 7 , no. 2, pp. 275-284, 2018.
[6] A. Uka, "Student Satisfaction As an Indicator of Quality in Higher Education," J. Educ. Instr. Stud., no. August, pp. 2146-7463, 2014

[7] E. Razinkina, L. Pankova, I. Trostinskaya, E. Pozdeeva, L. Evseeva, and A. Tanova, "Student satisfaction as an element of education quality monitoring in innovative higher education institution," E3S Web Conf., vol. 33, 2018, doi: 10.1051/e3sconf/20183303043.

[8] S. Herlambang, Hospital Health Service Management. Yogyakarta: Gosyen Publishing, 2016.

[9] J. Supranto, Measuring the Level of Customer Satisfaction to Increase Market Share. Jakarta: Rineka Cipta, 2011

[10] L. L. Berry, A. Parasuraman, and V. A. Zeithaml, "SERVQUAL: A multiple-item scale for measuring consumer perceptions of service quality," J. Retail., vol. 64, no. 1, pp. 12-40, 1988, doi: 10.1016/S01482963(99)00084-3.

[11] D. Kay and M. Pasarica, "Using technology to increase student (and faculty satisfaction with) engagement in medical education," Adv. Physiol. Educ., vol. 43, no. 3, pp. 408-413, 2019, doi: 10.1152/advan.00033.2019.

[12] A. Jiewanto, C. Laurens, and L. Nelloh, "Influence of Service Quality , University Image, and Student Satisfaction toward WOM Intention : A Case Study on Universitas Pelita Harapan Surabaya," Procedia - Soc Behav. Sci, vol. 40, pp. 16-23, 2012, doi 10.1016/j.sbspro.2012.03.155

[13] M. Bakrie, S. Bedjo, and Rugaiyah, "The Influence of Service Quality , Institutional Reputation, Students ' $\mathrm{S}$ atisfaction on Students ' Loyalty in Higher Education," vol. 1, no. 5, pp. 379-391, 2019.

[14] T. Chandra, N. Martha, S. Chandra, and Priyono, "The effect of service quality on student satisfaction and student loyalty: An empirical study," J. Soc. Stud. Educ. Res., vol. 9, no. 3, pp. 109-131, 2018, doi: $10.17499 /$ jsser. 12590

[15] K. Ali and M. A. Khan, "Impact of Service Quality ( SQ ) on Student Satisfaction : Empirical," no. July 2018.

[16] N. Gunawardhana, "Improving the Service Quality of Higher Education Institutions: Special reference to Information Systems," no. November 2018, 2019

[17] M. Hossein and M. Mozaffary, "Evaluation of quality of education in higher education based on Academic Quality Improvement Program ( AQIP ) Model," Procedia - Soc. Behav. Sci., vol. 15, pp. 2917-2922, 2011, doi: 10.1016/j.sbspro.2011.04.214

[18] P. I. Amos and Z. Hassan, "International Journal of Education, Learning and Training Quality of Teaching and its Influence on Student Satisfaction and Intention to Continue with Institution," Int. J. Educ. Learn. Train., vol. 2, no. 1, pp. 1-11, 2017, doi: 10.24924/ijelt/2017.04/v2.iss1/1.11

[19] S. Rapidah, O. Ali, N. A. Shariff, N. Shafini, M. Said, and K. A. Mat, "The Effects of Service Quality Dimensions o n Students ' Satisfaction Hedperf Model Adoption," vol. 15, no. 1, 2020.

[20] O. C. Hee, S. H. Ong, L. L. Ping, T. O. Kowang, and G. C. Fei, "Factors Influencing Job Satisfaction in the Higher Learning Institutions in Malaysia," Int. J. Acad. Res. Bus. Soc. Sci., vol. 9, no. 2, pp. 10-20, 2019, doi: 10.6007/ijarbss/v9-i2/5510.

[21] B. Al-Sheeb, A. M. Hamouda, and G. M. Abdella, "Investigating Determinants of Student Satisfaction in the First Year of College in a Public University in the State of Qatar,” Educ. Res. Int., vol. 2018, 2018 , doi: $10.1155 / 2018 / 7194106$ 